\title{
Identification of angiogenesis-related miRNAs in a population of patients with renal clear cell carcinoma
}

\author{
HE-CHENG LI*', JIAN-PING LI* , ZI-MING WANG, DE-LAI FU, ZHAO-LUN LI, \\ DONG ZHANG, WEI-MIN GAN and TIE CHONG
}

Department of Urology, The Second Affiliated Hospital, Xi'an Jiaotong University, Xi'an, Shaanxi 710004, P.R. China

Received May 12, 2014; Accepted June 16, 2014

DOI: $10.3892 /$ or.2014.3403

\begin{abstract}
In the present study, we compared the expression of miRNAs and angiogenesis-related genes in the renal tumors and adjacent normal renal tissues of patients with clear cell renal cell carcinoma (ccRCC). The first part of the present study was a preliminary analysis of 4 patients with stage $\mathrm{T} 1 \mathrm{a} / \mathrm{b}$ ccRCC that measured the levels of angiogenesis and expression of angiogenesis-related genes and miRNAs in the tumors and adjacent normal renal tissues. The second part of this study was an analysis of 30 patients with stage T1, T2 or T3 ccRCC that employed qPCR to characterize expression of angiogenesis-related miRNAs in the tumors and adjacent normal tissues. The first part of this study indicated that all 4 patients had increased levels of CD34 in tumors, indicating elevated angiogenesis. However, quantitative analysis of microvessel density and expression of miRNAs indicated highly variable results among these patients. The data of all patients in the present study indicated that more patients with stage T1 ccRCC had higher expression of miR-126 and miR-378 in their normal tissues, whereas more patients with stage T2/3 ccRCC had higher expression of these miRNAs in their tumor tissues. The tumors of patients with ccRCC had lower expression of miR-126 and miR-378 during the early stages of disease (T1), but higher expression of these miRNAs during the later stages of disease (T2/T3).
\end{abstract}

\section{Introduction}

The incidence of renal cell carcinoma (RCC) has increased steadily over the past 5 decades, and there are well-known demographic and lifestyle factors associated with increased risk $(1,2)$. Clear cell RCC (ccRCC) is the most common type

Correspondence to: Dr Tie Chong, Department of Urology, The Second Affiliated Hospital, Xi'an Jiaotong University, 157 Xiwu Road, Xi'an, Shaanxi 710004, P.R. China

E-mail: 1hch29@126.com

*Contributed equally

Key words: clear cell renal cell carcinoma, angiogenesis, CD34, miRNA, stage of cancer of RCC, and accounts for $\sim 75-88 \%$ of all cases $(3,4)$. ccRCC cells have clear cytoplasms due to accumulation of glycogen and lipids, and ccRCC tissue has high vascularity (2). Radical nephrectomy with removal of Gerota's fascia, perirenal fat and the ipsilateral adrenal gland is the most common treatment for RCC; however, 20-30\% of patients receiving nephrectomy nonetheless develop metastasis (2). Patients with metastatic RCC may be administered chemotherapy with FUDR, 5-FU, Taxol and carboplatin, but the response rate is poor (5) due to the development of multidrug resistance mediated by high expression of P-glycoprotein (6), an ABC-transporter that is responsible for drug efflux. Patients with late stage disease or distant metastases may have radical nephrectomy plus immunotherapy. Clinical studies have examined the effect of various targeted therapies, but the overall response rates were $<40 \%$ (2).

Solid tumors have reduced oxygen concentration, and this induces the accumulation of hypoxia-inducible factor (HIF) and increased expression of vascular endothelial growth factor (VEGF) (7). Recent studies have indicated that angiogenesis plays a key role in the pathogenesis of many solid tumors, including RCC (2). Accumulation and increased activity of $\mathrm{HIF}$, and increased expression of VEGF and PDGF, are associated with increased angiogenesis and metastatic potential of RCC $(8,9)$. Thus, several clinical studies of RCC have examined drugs that inhibit VEGF and PDGF receptors, such as sunitinib (10) and sorafenib (11).

Previous studies indicated that miRNAs are also involved in tumor angiogenesis $(12,13)$. In particular, many urologic tumors have altered levels of numerous miRNAs (14). Thus, altered expression of miRNAs may be useful for diagnosis, prediction of prognosis and treatment selection in patients with certain urologic cancers $(15,16)$. Notably, targeted disruption of angiogenesis-related miRNAs may be a potential treatment for RCC and other cancers (17). Previous research identified miR-210 as a hypoxia-regulated miRNA that was upregulated in RCC (18). Other research indicated that miR-29b, a negative regulator of VEGF, was also overexpressed in RCC (19). However, Hauser et al (20) studied RCC patients from Germany and reported that the serum levels of miR-26a-2, miR-191, miR-337-3p and miR-378 did not provide useful diagnostic or prognostic information. They also concluded that the level of miR-378 was unrelated to pT-stage, lymph node/ distant metastasis, vascular invasion and tumor grade. 
Our long-term purpose is to identify miRNAs that may be used as targets for novel ccRCC therapies. In the present study, we compared the expression of miRNAs and angiogenesis-related genes in the renal tumors and adjacent normal renal tissues of patients with ccRCC.

\section{Materials and methods}

Sample collection. The consecutive patients, who were admitted to the Second Affiliated Hospital of Xi'an Jiaotong University for treatment of ccRCC from October 2012 to July 2013, were included in the present study. In part I, tumor specimens and adjacent normal kidney tissues were isolated from 4 patients with stage T1a/b ccRCC and were examined by immunohistochemistry (IHC) and quantitative PCR (qPCR). The normal tissue of the fourth patient was used up in the pilot study, therefore no PCR data of this patient were available. In part II, biopsies from 30 consecutive ccRCC patients (23 with stage $\mathrm{T} 1 \mathrm{a} / \mathrm{b}$ cancer, 5 with stage $\mathrm{T} 2 \mathrm{a} / \mathrm{b}$ cancer, and 2 with stage T3a cancer) were used for qPCR analysis. All diagnoses and staging were made by ultrasonography and histological examination following established guidelines (21). Clinical data of these patients were collected from hospitalization and follow-up records. Samples were stored at $-80^{\circ} \mathrm{C}$ until RNA isolation. The medical ethics committee of the Second Affiliated Hospital of Xi'an Jiaotong University approved this study on March 8, 2010 (no. 2010029), and all patients provided written informed consent.

IHC. Samples $\left(3 \times 3 \times 3 \mathrm{~mm}^{3}\right)$ were fixed with $10 \%$ neutral buffered formalin at room temperature (RT) for $24 \mathrm{~h}$, and then embedded in paraffin for IHC analysis. For IHC staining of the vascular basement membrane, $7-\mu \mathrm{m}$-thick sections were prepared and the EnVision ${ }^{\mathrm{TM}}+$ System-HRP (DAB+) (DakoCytomation, France) was used for staining. Slides were incubated for 10 min with $3 \%$ hydrogen peroxide in distilled water to block endogenous peroxidase activity. After three washes with phosphate-buffered saline (PBS), sections were incubated for $30 \mathrm{~min}$ with $5 \%$ BSA in PBS to reduce non-specific binding. Sections were then incubated at RT for $1 \mathrm{~h}$ with monoclonal mouse anti-human CD34, CD31 or collagen-IV antibodies (IgG1, 1:50; DakoCytomation), washed in PBS, and then incubated in EnVision Polymer for $30 \mathrm{~min}$. A substrate-chromogen solution (DAB) was applied for $5 \mathrm{~min}$ and reactions were stopped by washing with distilled water. Finally, slides were counterstained with Mayer's hematoxylin for $1 \mathrm{~min}$.

IHC was also used to assess microvasculature density (MVD). For this analysis, 3- $\mu \mathrm{m}$ sections were subjected to epitope demarcation, and then IHC staining with a monoclonal antibody against CD34 (mouse anti-human CD34, code no. M7165, 1:50 dilution; Dako). After washing, a biotinconjugated secondary anti-mouse IgG antibody was applied at RT for $15 \mathrm{~min}$. Then, sections were exposed to the streptavidin-biotin-HRP complex and rinsed with the chromogen for $10 \mathrm{~min}$. After rinsing in water, sections were counter-stained with hematoxylin to visualize nuclei.

Quantification of $M V D$. An endothelial cell cluster or endothelial cell that was stained brown-yellow in IHC was considered as a single microvessel; undefined endothelial cell fragments and the visible vascular lumen were not counted as microvessels. A branching structure was considered to be a single vessel if there was no break in the continuity of the structure. Initially, the entire section was scanned for high-MVD areas at low magnification (x40 and x100) to identify hot spots (representing the highest vascular density). Then, stained endothelial clusters were counted under light microscopy at x200. The results are reported as mean microvessel counts of three hot spots under x200 magnification (20).

RNA extraction. Small (<200 bp) and large RNAs ( $>200$ bp) were isolated from tissue using the miRNeasy Mini kit and RNeasy MinElute Cleanup kit (Qiagen). The concentration of RNA was determined by a NanoDrop ND-1000 spectrophotometer (Thermo Scientific). RNA quality was assessed by the $18 \mathrm{~S} / 28 \mathrm{~S}$ pattern, and RNA was quantified by a NanoDrop-2000 spectrophotometer (Thermo Scientific, Wilmington, DE, USA).

Messenger RNA reverse transcription and real-time PCR quantification. A total of $2 \mu \mathrm{g}$ of large RNA ( $>200 \mathrm{bp}$ ) was reverse transcribed in a total volume of $25 \mu \mathrm{l}$ by use of $200 \mathrm{U}$ of M-MLV, $25 \mathrm{U}$ of RNase inhibitor, $2 \mu \mathrm{M}$ of random primer, $0.5 \mathrm{mM}$ dNTPs, and 1X RT buffer from Promega (Madison, WI, USA). The reaction was incubated at $37^{\circ} \mathrm{C}$ for $1 \mathrm{~h}$. Then, $2 \mu \mathrm{l}$ of RT products were subjected to SYBR-Green real-time PCR and the expression of VEGF, PDGF and HIF-1 $\alpha$ were determined relative to the housekeeping gene GAPDH: sense, 5'-CGGAGTCAACGGATTTGGTCGTATTGG-3' and antisense, 5'-GCTCCTGGAAGATGGTGATGGGATTTCC-3'. The following primer sequences were used: VEGF sense, 5'-ATCTGCATGGTGATGTTGGA-3' and antisense, 5'-GGG CAGAATCATCACGAAGT-3'; PDGF-A sense, 5'-CACACC TCCTCGCTGTAGTATTTA-3' and antisense, 5'-GTTATCG GTGTAAATGTCATCCAA-3'; PDGF-B sense, 5'-TCCCGA GGAGCTTTATGAGA-3' and antisense, 5'-ACTGCACGTTG CGGTTGT-3'; HIF- $1 \alpha$ sense, 5'-TTCACCTGAGCCTAA TAGTCC-3' and antisense, 5'-CAAGTCTAAATCTGTGTC CTG-3'. The relative expression levels of target RNAs were determined by the equation Ratio $=2^{-\Delta \Delta C \mathrm{CT}}$, with normalization to GAPDH. Expression in adjacent normal tissue was compared with expression in the carcinoma tissue.

miRNA reverse transcription and quantization. The levels of targeted angiogenesis-related miRNAs were quantified using SYBR-Green real-time PCR. Briefly, $100 \mathrm{ng}$ of isolated small RNA was reverse-transcribed using a stem-loop primer as described by Li et al (22). The RT product was subjected to real-time PCR to determine the level of miRNA expression. Ten miRNAs (miR-221, miR-222, miR-130a, let-7f-1, miR-27b, miR-378, miR-210, miR-15a, miR-16-1 and miR-126) were detected in the biopsies of patients in the first part of this study. Of the above 10 miRNAs, five highly expressed miRNAs (miR-15, miR-126, miR-210, miR-221 and miR-378) in the biopsies of the first part of this study were quantified in the 30 patients during the second part of the present study.

The PCR reactions were performed in triplicate, in two separate experiments. The housekeeping gene RNU44 snRNA was used for normalization (23). The relative expression of target miRNAs were determined as above (Ratio $=2^{-\Delta \Delta \mathrm{CT}}$ ). 


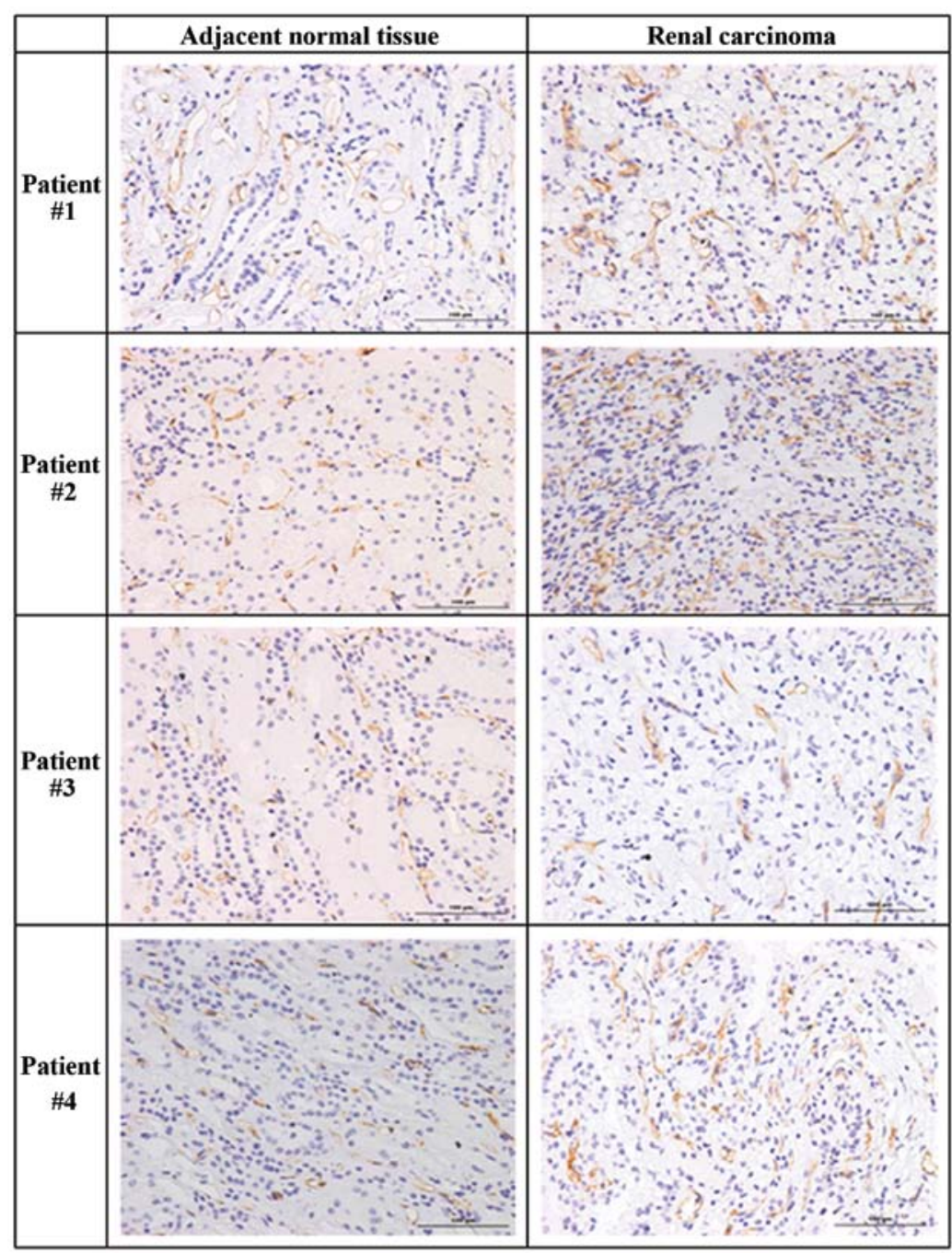

Figure 1. Microvasculature density in tumor tissues and adjacent normal tissues in 4 patients with ccRCC (part I). Scale bar represents $100 \mu \mathrm{m}$. Magnification, x200. ccRCC, clear cell renal cell carcinoma.

Expression in adjacent normal tissue was compared with expression in the carcinoma tissue.

Statistical analysis. Continuous variables are presented as means \pm standard deviations (SDs) and were compared by the independent two sample t-test. Categorical variables are presented as counts and percentages and were compared by Fisher's exact test. All statistical assessments were two-sided and evaluated at the 0.05 level of significance. Only 2 patients had stage T3 cancer, therefore patients who had stage T2 and $\mathrm{T} 3$ cancer $(\mathrm{n}=7)$ were compared with patients who had stage T1 cancer $(n=26)$ for assessment of the association of the miRNA expression in tumor and normal tissues and TNM classification. SAS software version 9.2 (SAS Institute Inc., Cary, NC, USA) was used for all statistical analysis.

\section{Results}

Part I: pilot study of 4 ccRCC patients

Angiogenesis in ccRCC tumors and adjacent normal tissues. We initially measured angiogenesis and the levels of angiogenesis-related genes in renal tumors and adjacent normal renal tissues in 4 patients with stage T1a/b ccRCC by use of IHC
Table I. Demographic characteristics of 4 patients with ccRCC (part I).

\begin{tabular}{llclc}
\hline Patient & Gender & $\begin{array}{c}\text { Age } \\
\text { (years) }\end{array}$ & $\begin{array}{c}\text { Affected } \\
\text { kidney }\end{array}$ & $\begin{array}{c}\text { TNM } \\
\text { classification }\end{array}$ \\
\hline$\# 1$ & Male & 58 & Left & T1a \\
$\# 2$ & Female & 49 & Left & T1b \\
$\# 3$ & Male & 49 & Right & T1b \\
$\# 4$ & Male & 54 & Right & T1a
\end{tabular}

ccRCC, clear cell renal cell carcinoma; TNM, tumor-node-metastasis.

(Table I). Compared to adjacent normal tissues, the tumors of the first three patients had increased levels of CD34, indicative of increased angiogenesis (Fig. 1, Table II). However, the normal tissue of the fourth patient had a slightly higher level of CD34. Analysis of MVD indicated greater counts in the tumors of patients \#1 and \#3, comparable counts in the normal and tumor tissues of patient \#4, but a markedly greater count in the normal tissue of patient \#2 (Table II). 

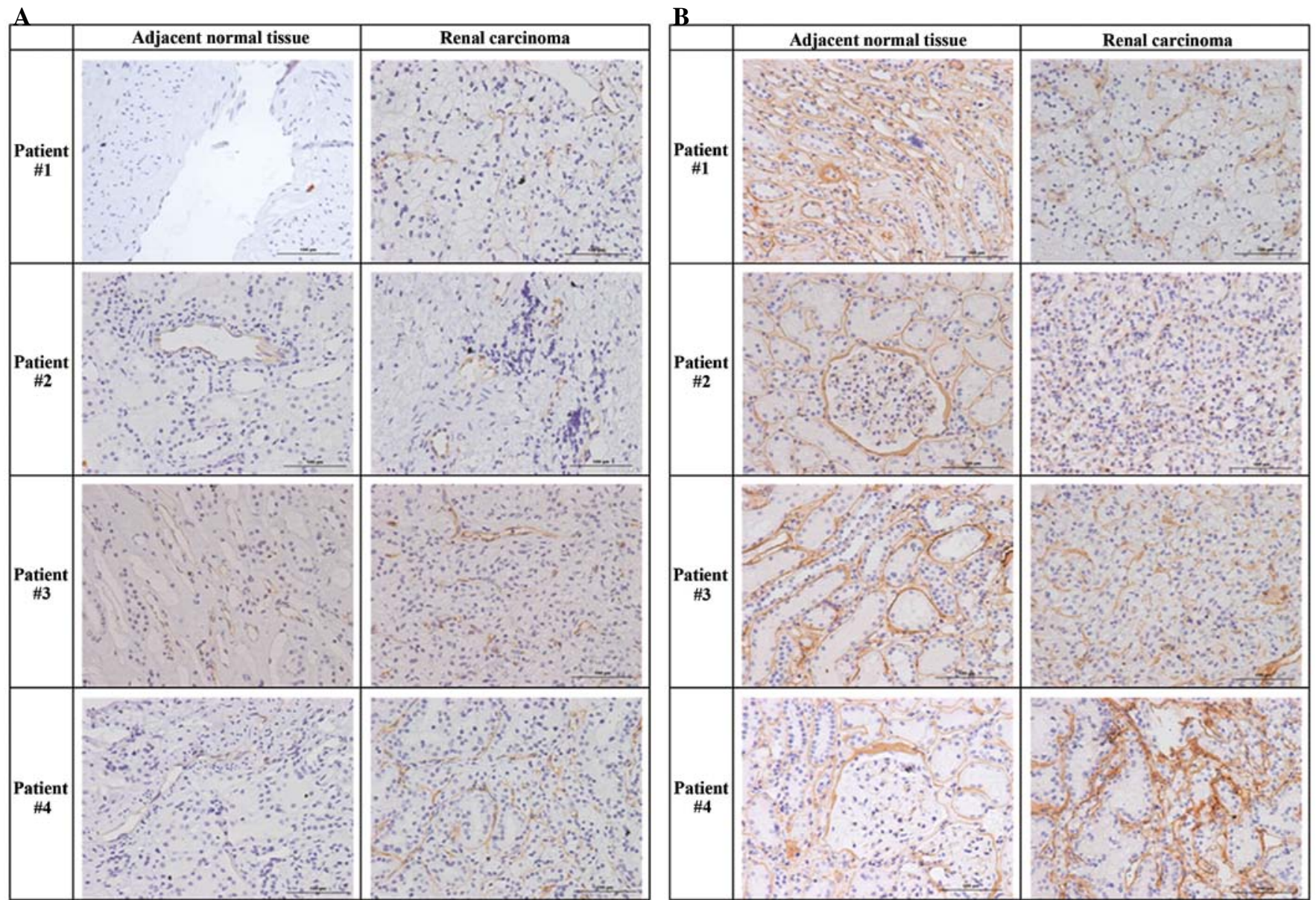

Figure 2. Immunohistochemistry for CD31 and collagen. (A) Expression of CD31 and (B) collagen in tumor tissues and adjacent normal tissues (venule basement membrane) in 4 patients with ccRCC. Scale bar represents $100 \mu \mathrm{m}$. Magnification, x200. ccRCC, clear cell renal cell carcinoma.

Table II. Microvessel density (MVD) and CD34 expression in normal renal tissue and renal tumor tissue of 4 patients with $\operatorname{ccRCC}($ part I).

\begin{tabular}{llcc}
\hline Patient & Tissue & MVD count & CD34 (avg. OD) \\
\hline$\# 1$ & Normal & $68.33 \pm 16.62$ & $4.54 \pm 0.30$ \\
& Tumor & $99.33 \pm 13.65$ & $6.38 \pm 0.53$ \\
$\# 2$ & Normal & $150.33 \pm 7.37$ & $4.91 \pm 0.46$ \\
& Tumor & $56.67 \pm 3.06$ & $5.81 \pm 1.54$ \\
$\# 3$ & Normal & $37.67 \pm 14.01$ & $4.43 \pm 1.77$ \\
& Tumor & $59.67 \pm 15.01$ & $6.16 \pm 2.45$ \\
$\# 4$ & Normal & $79.67 \pm 8.08$ & $4.59 \pm 1.38$ \\
& Tumor & $75.00 \pm 17.09$ & $3.84 \pm 0.32$ \\
\hline
\end{tabular}

ccRCC, clear cell renal cell carcinoma.

Venule basement membranes in ccRCC tumors and adjacent normal tissues. Next, we used antibodies against CD31 (Fig. 2A) and collagen IV (Fig. 2B) to evaluate the integrity of the venule basement membranes of renal tumors and adjacent normal renal tissues. The results indicated that collagen IV staining was stronger in the basement membranes of normal tissues and that the basement membranes of renal tumor tissues were less intact than adjacent normal tissues. In particular, there were no regular circular structures and only small luminal regions in the tumor tissues (Fig. 2).

Expression of HIF-1a, PDGF-A, PDGF-B and VEGF-A in $c c R C C$ tumors and adjacent normal tissues. We measured the expression of angiogenesis-related genes in renal tumors and adjacent normal renal tissues from 3 of these $4 \mathrm{ccRCC}$ patients by use of qPCR (Fig. 3). There was no remaining normal tissue of the fourth patient, therefore these qPCR data are not available. The results indicated significantly lower expression of HIF-1 $\alpha$ in the tumors of all 3 patients (Fig. 3A). This was somewhat unexpected since tumors have reduced oxygen concentration and this has been shown to induce HIF accumulation.

The expression of PDGF-A was significantly lower in the tumor tissues of patients \#2 and \#3, but was not significantly different in the tumor and normal tissues of patient \#1 (Fig. 3B). The expression of PDGF-B was similar in the tumor and normal tissues of patient \#1, higher in the tumor tissues of patient \#2, and higher in the normal tissues of patient \#3 (Fig. 3C). The expression of VEGF-A was higher in the tumor tissues of patients \#1 and \#2, but similar in the tumor and normal tissues of patient \#3 (Fig. 3D). Collectively, these data indicate significant inter-individual variation in the expression of these 4 angiogenesis-related genes. 
A

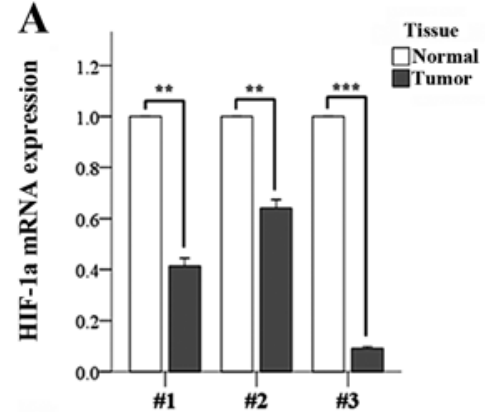

C

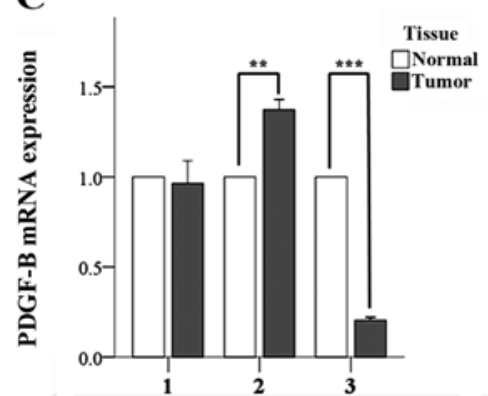

B

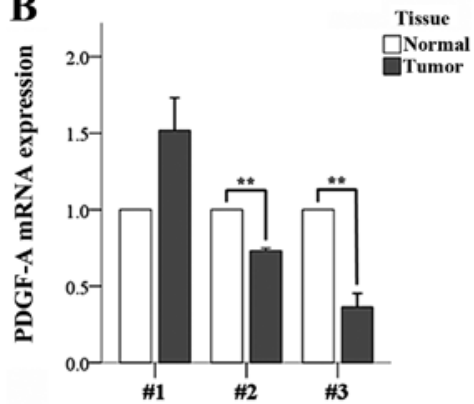

D

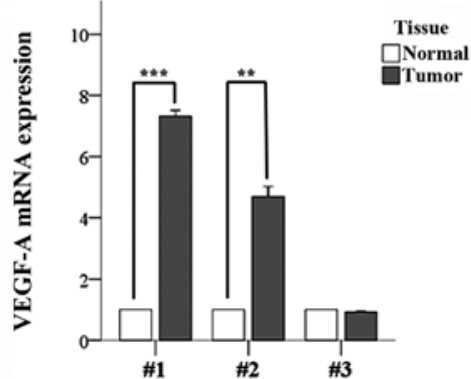

Figure 3. mRNA expression of HIF-1 $\alpha$, PDGF-A, PDGF-B and VEGF-A. mRNA samples prepared from tumor tissues and adjacent normal tissues in 3 patients with ccRCC (part I) were subjected to mRNA quantification for (A) HIF-1 $\alpha$, (B) PDGF-A, (C) PDGF-B and (D) VEGF-A. Data (n=3) are expressed as means \pm SDs. ${ }^{* *} \mathrm{p}<0.01 ;{ }^{* * *} \mathrm{p}<0.001$. ccRCC, clear cell renal cell carcinoma.

Table III. Expression of miRNAs in tumor tissue relative to adjacent normal tissue in 3 patients with ccRCC (part I).

\begin{tabular}{lccl}
\hline Patient & miRNA & Tumor tissue/normal tissue & P-value \\
\hline$\# 1$ & Hsa-miR-210 & $1.57 \pm 0.34$ & 0.253 \\
& Hsa-miR-378 & $(3.7 \pm 3.6) \times 10^{-5}$ & $0.017^{\mathrm{a}}$ \\
$\# 2$ & Hsa-miR-210 & $7.87 \pm 5.86$ & 0.179 \\
$\# 3$ & Hsa-miR-210 & $20.82 \pm 20.4$ & 0.235 \\
\hline
\end{tabular}

The data represent mean fold-changes \pm SDs of expression in tumor tissue relative to the corresponding normal tissue. ${ }^{\text {aSignificantly lower }}$ expression in tumor tissue. ccRCC, clear cell renal cell carcinoma; SDs, standard deviations.

Angiogenesis-related miRNA expression. A comparison of the differential expression of miRNAs in normal and cancer tissues of these 3 patients led to identification of 2 miRNAs, Hsa-miR-210 and Hsa-miR-378 (Table III). The results indicated significantly lower expression of Hsa-miR-378 in the tumor of patient \#1. In addition, all 3 patients had higher expression of Hsa-miR-210 in the tumor tissues, although these differences were not significant.

Part II: validation study with 30 ccRCC patients. Subsequently, we extended the results of the pilot study by analyzing miRNA expression in 30 additional ccRCC patients, 23 with stage $\mathrm{T} 1 \mathrm{a} / \mathrm{b}$ cancer, 5 with stage T2a/b cancer, and 2 with stage T3a cancer (Table IV). Table V shows the relative expression (tumor tissue/normal tissue) of 5 selected miRNAs (miR-15, miR-126, miR-210, miR-221 and miR-378) in each of the 30 patients.
Table IV. Demographic characteristics of 30 patients with ccRCC (part II).

Characteristics Mean \pm SD or $n(\%)$

Age, years

$57.0 \pm 11.3$

Gender

Male

19 (36.7)

Female

Affected kidney

Left

Right

TNM classification

T1a

T1b

$\mathrm{T} 2 \mathrm{a}$

$\mathrm{T} 2 \mathrm{~b}$

T3a

2 (6.7)

ccRCC, clear cell renal cell carcinoma; SD, standard deviation; TNM, tumor-node-metastasis.

Statistical analysis of pooled data from both parts. In order to increase the sample size, the data of both parts were pooled together. Table VI shows the expression of 5 miRNAs (miR-15, miR-126, miR-210, miR-221 and miR-378) in all 33 ccRCC patients, with classification into 5 categories (normal $>$ tumor, tumor $>$ normal, undetected in tumor, undetected in normal tissue, and undetected in both tissues).

Finally, we separated these 33 patients into two groups, one with stage T1 ccRCC $(n=26)$ and one with stage T2/T3 
Table V. Expression of 5 different miRNAs in tumor tissue relative to adjacent normal tissue (mean \pm SD) in 30 patients with ccRCC (part II).

\begin{tabular}{|c|c|c|c|}
\hline Patient & Tumor tissue/normal tissue & P-value & \\
\hline \multicolumn{3}{|l|}{$\# 1$} & Hsa-miR-378 \\
\hline Hsa-miR-15 & $(40.88 \pm 25.25) \times 10^{-1}$ & 0.168 & \#14 \\
\hline Hsa-miR-126 & $0.14 \pm 0.07$ & $0.002^{\mathrm{a}}$ & Hsa-miR-15 \\
\hline Hsa-miR-210 & $11.88 \pm 1.37$ & $0.005^{\mathrm{a}}$ & Hsa-miR-126 \\
\hline Hsa-miR-221 & $(2.29 \pm 1.84) \times 10^{-1}$ & $0.018^{\mathrm{a}}$ & Hsa-miR_-210 \\
\hline Hsa-miR-378 & $(10.67 \pm 1.77) \times 10^{-5}$ & $<0.001^{\mathrm{a}}$ & $\begin{array}{l}\text { Hsa-miR-210 } \\
\text { Hsa-miR-378 }\end{array}$ \\
\hline \multicolumn{3}{|l|}{ \#2 } & \#15 \\
\hline Hsa-miR-15 & $(1.02 \pm 0.53) \times 10^{-1}$ & $0.001^{\mathrm{a}}$ & \\
\hline Hsa-miR-126 & $0.18 \pm 0.18$ & 0.016 & Hsa-miR-126 \\
\hline Hsa-miR-210 & $1.96 \pm 0.4$ & 0.053 & Hsa-miR-210 \\
\hline Hsa-miR-221 & $(0.67 \pm 0.46) \times 10^{-1}$ & $0.001^{\mathrm{a}}$ & Hsa-miR-378 \\
\hline Hsa-miR-378 & $(7.52 \pm 2.05) \times 10^{-5}$ & $<0.001^{\mathrm{a}}$ & $\# 16$ \\
\hline \multicolumn{3}{|l|}{$\# 3$} & Hsa-miR-126 \\
\hline Hsa-miR-15 & $(4.68 \pm 4.61) \times 10^{-1}$ & 0.184 & Hsa-miR-210 \\
\hline Hsa-miR-126 & $0.12 \pm 0.07$ & $0.002^{\mathrm{a}}$ & Hsa-miR-221 \\
\hline Hsa-miR-210 & $6.18 \pm 2.13$ & 0.052 & Hsa-miR-378 \\
\hline Hsa-miR-221 & $(3.39 \pm 1.35) \times 10^{-1}$ & $0.014^{\mathrm{a}}$ & $\# 17$ \\
\hline Hsa-miR-378 & $(27.33 \pm 9.72) \times 10^{-5}$ & $0.006^{\mathrm{a}}$ & Hsa-miR-126 \\
\hline \multicolumn{3}{|l|}{ \#4 } & Hsa-miR-210 \\
\hline Hsa-miR-210 & $6.2 \pm 1.14$ & $0.016^{\mathrm{a}}$ & Hsa-miR-221 \\
\hline Hsa-miR-378 & $(7.99 \pm 6.7) \times 10^{-5}$ & $0.002^{\mathrm{a}}$ & Hsa-miR-378 \\
\hline \multicolumn{3}{|l|}{ \#5 } & \#18 \\
\hline Hsa-miR-210 & $0.09 \pm 0.01$ & $<0.001^{\mathrm{a}}$ & Hsa-miR-126 \\
\hline Hsa-miR-378 & $(0.18 \pm 0.09) \times 10^{-5}$ & $<0.001^{\mathrm{a}}$ & Hsa-miR-210 \\
\hline \multicolumn{3}{|l|}{ \#6 } & Hsa-miR-221 \\
\hline Hsa-miR-210 & $39.97 \pm 4.72$ & $0.005^{\mathrm{a}}$ & Hsa-miR-378 \\
\hline Hsa-miR-378 & $(546.99 \pm 179.83) \times 10^{-5}$ & $0.050^{\mathrm{a}}$ & $\# 19$ \\
\hline \multicolumn{3}{|l|}{ \#7 } & Hsa-miR-126 \\
\hline Hsa-miR-210 & $3.84 \pm 1.1$ & $0.047^{\mathrm{a}}$ & Hsa-miR-210 \\
\hline Hsa-miR-378 & $(375.4 \pm 109.99) \times 10^{-5}$ & $0.049^{\mathrm{a}}$ & Hsa-miR-221 \\
\hline \multicolumn{3}{|l|}{ \#8 } & Hsa-miR-378 \\
\hline Hsa-miR-126 & $0.11 \pm 0.03$ & $<0.001^{\mathrm{a}}$ & $\# 20$ \\
\hline Hsa-miR-210 & $1.13 \pm 0.04$ & $0.035^{\mathrm{a}}$ & Hsa-miR-15 \\
\hline Hsa-miR-378 & $(20.59 \pm 4.88) \times 10^{-5}$ & $0.001^{\mathrm{a}}$ & Hsa-miR-126 \\
\hline \multicolumn{3}{|l|}{ \#9 } & Hsa-miR-210 \\
\hline Hsa-miR-15 & $(14.83 \pm 2.99) \times 10^{-1}$ & 0.263 & Hsa-miR-221 \\
\hline Hsa-miR-126 & $0.28 \pm 0.08$ & $0.004^{\mathrm{a}}$ & Hsa-miR-378 \\
\hline Hsa-miR-210 & $7.18 \pm 0.25$ & $0.001^{\mathrm{a}}$ & $\# 21$ \\
\hline Hsa-miR-221 & $(3.41 \pm 2.33) \times 10^{-1}$ & $0.039^{\mathrm{a}}$ & Hsa-miR-210 \\
\hline Hsa-miR-378 & $(4.9 \pm 0.78) \times 10^{-5}$ & $<0.001^{\mathrm{a}}$ & Hsa-miR-378 \\
\hline \multicolumn{3}{|l|}{$\# 10$} & \#22 \\
\hline Hsa-miR-15 & $(86.91 \pm 26.36) \times 10^{-1}$ & 0.151 & Hsa-m \\
\hline Hsa-miR-210 & $5.84 \pm 1.5$ & $0.031^{\mathrm{a}}$ & Hsa-miR-378 \\
\hline Hsa-miR-378 & $(78.61 \pm 32.97) \times 10^{-5}$ & 0.378 & Hsa-miR-378 \\
\hline \multicolumn{3}{|l|}{ \#11 } & \#23 \\
\hline Hsa-miR-210 & $0.14 \pm 0.02$ & $<0.001^{\mathrm{a}}$ & Hsa-miR-210 \\
\hline Hsa-miR-378 & $(2372.67 \pm 472.7) \times 10^{-5}$ & $0.014^{\mathrm{a}}$ & Hsa-miR-378 \\
\hline \multicolumn{3}{|l|}{ \#12 } & $\# 24$ \\
\hline Hsa-miR-210 & $0.58 \pm 0.12$ & $0.026^{\mathrm{a}}$ & Hsa-miR-210 \\
\hline Hsa-miR-378 & $(763.96 \pm 67.22) \times 10^{-5}$ & $0.003^{\mathrm{a}}$ & Hsa-miR-378 \\
\hline
\end{tabular}

Table V. Continued.

Patient Tumor tissue/normal tissue P-value

$\begin{array}{cc}17.85 \pm 2.27 & 0.006^{\mathrm{a}} \\ (234.96 \pm 38.94) \times 10^{-5} & 0.027^{\mathrm{a}} \\ & \\ (1.68 \pm 1.23) \times 10^{-1} & 0.066 \\ 0.68 \pm 0.42 & 0.477 \\ 14.13 \pm 5.32 & 0.051 \\ (14.25 \pm 2.13) \times 10^{-5} & <0.001^{\mathrm{a}} \\ & \\ 0.6 \pm 0.34 & 0.178 \\ 5.3 \pm 0.77 & 0.010^{\mathrm{a}} \\ (0.38 \pm 0.03) \times 10^{-5} & <0.001^{\mathrm{a}}\end{array}$

$\begin{array}{cl}60.46 \pm 26.13 & 0.059 \\ 0.42 \pm 0.04 & 0.002^{\mathrm{a}} \\ (48.46 \pm 16.84) \times 10^{-1} & 0.058 \\ (427.57 \pm 117.62) \times 10^{-5} & 0.040^{\mathrm{a}}\end{array}$

$1.15 \pm 0.64 \quad 0.718$

$4.98 \pm 0.4 \quad 0.003^{\mathrm{a}}$

$(1.38 \pm 0.95) \times 10^{-1} \quad 0.004^{\mathrm{a}}$

$(6.95 \pm 2.38) \times 10^{-5} \quad<0.001^{\mathrm{a}}$

$0.38 \pm 0.21$

0.151

$8.37 \pm 0.27$

$<0.001^{\mathrm{a}}$

$(0.35 \pm 0.03) \times 10^{-1} \quad 0.001^{\mathrm{a}}$

$(21.9 \pm 5.48) \times 10^{-5} \quad 0.002^{\mathrm{a}}$

$0.87 \pm 1.34 \quad 0.880$

$24.4 \pm 2.04 \quad 0.003^{\mathrm{a}}$

$(1.61 \pm 0.75) \times 10^{-1} \quad 0.003^{\mathrm{a}}$

$(51.92 \pm 24.64) \times 10^{-5} \quad 0.078$

$\begin{array}{ll}(7.66 \pm 8.3) \times 10^{-1} & 0.758\end{array}$

$0.24 \pm 0.16 \quad 0.093$

$10.9 \pm 0.49 \quad 0.001^{\mathrm{a}}$

$(1.75 \pm 0.99) \times 10^{-1} \quad 0.005^{\mathrm{a}}$

$(21.8 \pm 7.91) \times 10^{-5} \quad 0.003^{\mathrm{a}}$

$5.66 \pm 0.23 \quad 0.001^{\mathrm{a}}$

$(135.14 \pm 57.35) \times 10^{-5} \quad 0.400$

$37.32 \pm 3.94 \quad 0.004^{\mathrm{a}}$

$(1.4 \pm 0.84) \times 10^{-5} \quad<0.001^{\mathrm{a}}$

$4.4 \pm 0.26 \quad 0.002^{\mathrm{a}}$

$(5.27 \pm 0.5) \times 10^{-5} \quad<0.001^{\mathrm{a}}$

$5.44 \pm 0.33 \quad 0.002^{\mathrm{a}}$

$(6.82 \pm 1.79) \times 10^{-5} \quad<0.001^{\mathrm{a}}$ 
Table V. Continued.

\begin{tabular}{|c|c|c|}
\hline Patient & Tumor tissue/normal tissue & P-value \\
\hline \multicolumn{3}{|l|}{$\# 25$} \\
\hline Hsa-miR-210 & $46.69 \pm 3.06$ & $0.001^{\mathrm{a}}$ \\
\hline Hsa-miR-378 & $(648.45 \pm 122.55) \times 10^{-5}$ & $0.016^{\mathrm{a}}$ \\
\hline \multicolumn{3}{|l|}{ \#26 } \\
\hline Hsa-miR-15 & $(3.67 \pm 2.66) \times 10^{-1}$ & 0.184 \\
\hline Hsa-miR-210 & $8.64 \pm 0.25$ & $<0.001^{\mathrm{a}}$ \\
\hline Hsa-miR-378 & $(16.7 \pm 3.24) \times 10^{-5}$ & $0.001^{\mathrm{a}}$ \\
\hline \multicolumn{3}{|l|}{ \#27 } \\
\hline Hsa-miR-210 & $6.79 \pm 0.57$ & $0.003^{\mathrm{a}}$ \\
\hline Hsa-miR-378 & $(31.05 \pm 5.32) \times 10^{-5}$ & $0.002^{\mathrm{a}}$ \\
\hline \multicolumn{3}{|l|}{ \#28 } \\
\hline Hsa-miR-15 & $(13.2 \pm 11.75) \times 10^{-1}$ & 0.683 \\
\hline Hsa-miR-126 & $0.73 \pm 0.4$ & 0.358 \\
\hline Hsa-miR-210 & $0.57 \pm 0.02$ & $0.001^{\mathrm{a}}$ \\
\hline Hsa-miR-221 & $(5.4 \pm 3.52) \times 10^{-1}$ & 0.152 \\
\hline Hsa-miR-378 & $(69.89 \pm 21.32) \times 10^{-5}$ & 0.134 \\
\hline \multicolumn{3}{|l|}{$\# 29$} \\
\hline Hsa-miR-15 & $(0.33 \pm 0.39) \times 10^{-1}$ & $0.001^{\mathrm{a}}$ \\
\hline Hsa-miR-126 & $0.23 \pm 0.09$ & $0.005^{\mathrm{a}}$ \\
\hline Hsa-miR-210 & $7.27 \pm 0.49$ & $0.002^{\mathrm{a}}$ \\
\hline Hsa-miR-221 & $(0.09 \pm 0.06) \times 10^{-1}$ & $<0.001^{\mathrm{a}}$ \\
\hline Hsa-miR-378 & $(11.35 \pm 1.66) \times 10^{-5}$ & $<0.001^{\mathrm{a}}$ \\
\hline \multicolumn{3}{|l|}{ \#30 } \\
\hline Hsa-miR-15 & $(99.34 \pm 159.82) \times 10^{-1}$ & 0.435 \\
\hline Hsa-miR-126 & $0.74 \pm 0.53$ & 0.492 \\
\hline Hsa-miR-210 & $3.87 \pm 0.49$ & $0.010^{\mathrm{a}}$ \\
\hline Hsa-miR-221 & $(2.72 \pm 3.79) \times 10^{-1}$ & 0.080 \\
\hline Hsa-miR-378 & $(4.77 \pm 0.92) \times 10^{-5}$ & $<0.001^{\mathrm{a}}$ \\
\hline
\end{tabular}

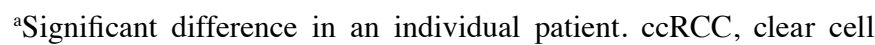
renal cell carcinoma.

ccRCC $(n=7)$ (Table VII). Statistical analysis of these results indicated that expression of Hsa-miR-126 and Hsa-miR-378 were associated with pathological status, although the $\mathrm{p}$-values only indicated marginal significance $(\mathrm{p}=0.042$ and $\mathrm{p}=0.047)$. In particular, more patients with stage I ccRCC had higher expression of both miRNAs in their normal tissues, and more patients with stage T2/T3 ccRCC had higher expression of both miRNAs in their tumors.

\section{Discussion}

The initial study of 4 patients with ccRCC indicated increased levels of CD34 in the tumors of all patients, consistent with the presence of increased angiogenesis. In agreement with this result, the venual basement membranes in their tumor tissues were disrupted and had greatly reduced lumens, reduced expression of collagen, and reduced expression of CD31. However, quantitative analysis of microvessel density (MVD) and expression of miRNAs in the same patients produced variable results. Three of the 4 patients had higher microvessel density in their tumors, but 1 patient had markedly higher MVD in the normal tissue. In addition, there were similar levels of miR-210 in the tumor and normal tissues of all tested patients, and only 1 patient had significantly lower expression of miR-378 in the tumor tissue relative to normal tissue. The second part of this study indicated that more patients with stage $\mathrm{T} 1 \mathrm{a} / \mathrm{b}$ cancer had higher expression of miR-126 and miR-378 in their normal tissues, and that more patients with stage T2/T3 cancer had higher expression of these miRNAs in their cancerous tissues.

Previous studies have also documented differential expression of angiogenesis-related molecules in ccRCC tumors. In particular, Esteban et al (24) reported that the level of HIF-1 $\alpha$ mRNA was lower in ccRCC tumor tissues than in adjacent normal tissues. Our results also indicated significantly lower expression of HIF-1 $\alpha$ in the tumor tissues of 3 tested patients. These results apparently contradict the hypothesis that reduced oxygen concentration in tumor tissue induces accumulation of HIF (7). However, the study of Esteban et al (24) demonstrated the loss of function of the von Hippel-Lindau (VHL) tumor suppressor gene in the majority of patients with ccRCC, and that this led to downregulation of HIF-1 $\alpha$ mRNA through epigenetic regulation. The results of this study are consistent with this.

Redova et al (25) used TaqMan low-density arrays to identify differentially expressed miRNAs in tumor and adjacent normal tissues of patients with ccRCC. They identified 667 miRNAs, 78 of which were differentially expressed (73 miRNAs were downregulated in tumors and 5 miRNAs were upregulated in tumors). Other research identified 10 miRNAs (miR-221, miR-222, miR-130a, let-7f-1, miR-27b, miR-378, miR-210, miR-15a, miR-16-1 and miR-126) that were putatively involved in angiogenesis based on analysis of tumor and adjacent normal tissues of patients with ccRCC (22). In agreement with this result, we found that the tumors of patients with stage $\mathrm{T} 1 \mathrm{ccRCC}$ had significantly lower tumor expression of 2 of the same miRNAs (miR-126 and miR-378) than the tumors of patients with stage T2/T3 ccRCC. Our results are also consistent with the report of Redova et al (25) who found that more miRNAs were downregulated in ccRCC tissues than in normal tissues (73 of 78 miRNAs). Notably, several studies of non-small cell lung cancer (NSCLC) have also indicated an important role for miR-378 in tumor progression and angiogenesis $(26,27)$. This miRNA appears to target the tumor suppressors Sufu and Fus-1 (28). Another study on NSCLC indicated an important role of miR-126 (29) which targets EGFL7 in metastasis and angiogenesis.

Our results are also consistent with previous studies that reported disrupted miR-378 expression in tumor tissues. One study reported increased levels of miR-378 in the serum of patients with ccRCC (20) and another study reported overexpression of miR-378 in human non-small cell lung carcinoma and an association of expression with enhanced tumor proliferation and migration (26). However, in the present study, miR-378 levels were lower in tumor samples than in normal tissues. This observation raises the possibility that miR-378 may play a role that is unrelated to angiogenesis in the pathogenesis of ccRCC.

The initial study of 4 patients with ccRCC indicated marked differences in the expression of angiogenesis-related genes 
Table VI. Differential expression of 5 miRNAs in normal and tumor tissues of 33 patients with ccRCC.

Expression in normal vs. tumor tissue

\begin{tabular}{lccccc}
\cline { 2 - 5 } miRNA & Normal $>$ tumor & Tumor $>$ normal & $\begin{array}{c}\text { Undetected in } \\
\text { tumor tissue }\end{array}$ & $\begin{array}{c}\text { Undetected in } \\
\text { normal tissue }\end{array}$ & $\begin{array}{c}\text { Undetected in } \\
\text { both tissues }\end{array}$ \\
\hline Hsa-miR-15 & 6 & 7 & 5 & 8 & 7 \\
Hsa-miR-126 & 15 & 4 & 4 & 1 & 9 \\
Hsa-miR-210 & 6 & 27 & 0 & 0 & 0 \\
Hsa-miR-221 & 11 & 2 & 8 & 3 & 9 \\
Hsa-miR-378 & 23 & 8 & 1 & 1 & 1 \\
\hline
\end{tabular}

ccRCC, clear cell renal cell carcinoma.

Table VII. Association between expression of specific miRNAs in tumor and normal tissues and TNM classification of 33 patients with ccRCC.

\begin{tabular}{|c|c|c|c|}
\hline miRNA & $\mathrm{T} 1 \mathrm{n}(\%)$ & $\mathrm{T} 2$ and $\mathrm{T} 3 \mathrm{n}(\%)$ & P-value \\
\hline Hsa-miR-15 & & & 0.128 \\
\hline Normal $>$ tumor $^{\mathrm{a}}$ & $7(33.3)$ & $4(80.0)$ & \\
\hline Tumor $>$ normal $^{b}$ & $14(66.7)$ & $1(20.0)$ & \\
\hline Hsa-miR-126 & & & $0.042^{\mathrm{c}}$ \\
\hline Normal $>$ tumor ${ }^{\mathrm{a}}$ & $17(89.5)$ & $2(40.0)$ & \\
\hline Tumor $>$ normal $^{\mathrm{b}}$ & $2(10.5)$ & $3(60.0)$ & \\
\hline Hsa-miR-210 & & & 0.093 \\
\hline Normal $>$ tumor $^{\mathrm{a}}$ & $3(11.5)$ & $3(42.9)$ & \\
\hline Tumor $>$ normal $l^{b}$ & $23(88.5)$ & $4(57.1)$ & \\
\hline Hsa-miR-221 & & & 0.179 \\
\hline Normal $>$ tumor & $17(85.0)$ & $2(50.0)$ & \\
\hline Tumor $>$ normal $l^{\mathrm{b}}$ & $3(15.0)$ & $2(50.0)$ & \\
\hline Hsa-miR-378 & & & $0.047^{\mathrm{c}}$ \\
\hline Normal $>$ tumor & $21(84.0)$ & $3(42.9)$ & \\
\hline Tumor $>$ normal $l^{b}$ & $4(16.0)$ & $4(57.1)$ & \\
\hline
\end{tabular}

${ }^{a}$ The normal $>$ tumor group includes the expression pattern of normal $>$ tumor and tumor undetermined; b the tumor $>$ normal group includes the expression pattern of normal undetermined. Fisher's exact test was used for comparisons. 'Significant difference between groups. TNM, tumor-node-metastasis. ccRCC, clear cell renal cell carcinoma.

among these patients, although they all had stage T1a/b cancer. This suggests the importance of using large sample sizes, and indicates that the results we obtained with 33 patients may not be generalizable to other populations. A large-scale study is required to confirm the findings presented here.

In conclusion, the tumor tissues of patients who had ccRCC in the present study had decreased expression of miR-126 and miR-378 during the early stages of cancer (T1), but increased expression miR-126 and miR-378 during the later stages of disease (T2/T3). These results suggest that these miRNAs play a role in the pathogenesis of ccRCC.

\section{Acknowledgements}

This study was supported by a grant from the Natural Science Foundation of China (General Program) no. 81072106. The authors are grateful to Dr Qin from the Department of Urology, The Second Affiliated Hospital, Xi'an Jiaotong University for assistance with biopsy collection.

\section{References}

1. Parkin DM, Pisani P and Ferlay J: Estimates of the worldwide incidence of 25 major cancers in 1990. Int J Cancer 80: 827-841, 1999.

2. Koul H, Huh JS, Rove KO, Crompton L, Koul S, Meacham RB and Kim FJ: Molecular aspects of renal cell carcinoma: a review. Am J Cancer Res 1: 240-254, 2011.

3. Patard JJ, Leray E, Rioux-Leclercq N, Cindolo L, Ficarra V, Zisman A, De La Taille A, et al: Prognostic value of histologic subtypes in renal cell carcinoma: a multicenter experience. J Clin Oncol 23: 2763-2771, 2005.

4. Schachter LR, Cookson MS, Chang SS, Smith JA Jr, Dietrich MS, Jayaram G and Herrell SD: Second prize: frequency of benign renal cortical tumors and histologic subtypes based on size in a contemporary series: what to tell our patients. J Endourol 21: 819-823, 2007.

5. Rini BI, Vogelzang NJ, Dumas MC, Wade JL III, Taber DA and Stadler WM: Phase II trial of weekly intravenous gemcitabine with continuous infusion fluorouracil in patients with metastatic renal cell cancer. J Clin Oncol 18: 2419-2426, 2000.

6. Yagoda A, Abi-Rached B and Petrylak D: Chemotherapy for advanced renal-cell carcinoma: 1983-1993. Semin Oncol 22: 42-60, 1995.

7. Sarkar S and Suresh MR: An overview of tuberculosis chemotherapy-a literature review. J Pharm Pharm Sci 14: 148-161, 2011.

8. Billemont B, Méric JB, Izzedine $\mathrm{H}$, et al: Angiogenesis and renal cell carcinoma. Bull Cancer 94: S232-S240, 2007 (In French).

9. Lainakis $\mathrm{G}$ and Bamias A: Targeting angiogenesis in renal cell carcinoma. Curr Cancer Drug Targets 8: 349-358, 2008.

10. Rini BI: VEGF-targeted therapy in metastatic renal cell carcinoma. Oncologist 10: 191-197, 2005.

11. Ahmad T and Eisen T: Kinase inhibition with BAY 43-9006 in renal cell carcinoma. Clin Cancer Res 10: 6388S-6392S, 2004.

12. Suárez Y and Sessa WC: MicroRNAs as novel regulators of angiogenesis. Circ Res 104: 442-454, 2009.

13. Bridge G, Monteiro R, Henderson S, et al: The microRNA-30 family targets $D L L 4$ to modulate endothelial cell behavior during angiogenesis. Blood 120: 5063-5072, 2012.

14. Catto JW, Alcaraz A, Bjartell AS, et al: MicroRNA in prostate, bladder, and kidney cancer: a systematic review. Eur Urol 59: 671-681, 2011.

15. Schaefer A, Jung M, Kristiansen G, et al: MicroRNAs and cancer: current state and future perspectives in urologic oncology. Urol Oncol 28: 4-13, 2010. 
16. Ru Y, Dancik GM and Theodorescu D: Biomarkers for prognosis and treatment selection in advanced bladder cancer patients. Curr Opin Urol 21: 420-427, 2011.

17. Fendler A, Stephan C, Yousef GM and Jung K: MicroRNAs as regulators of signal transduction in urological tumors. Clin Chem 57: 954-968, 2011.

18. Weng L, Wu X, GaoH, et al: MicroRNA profiling of clearcell renal cell carcinoma by whole-genome small RNA deep sequencing of paired frozen and formalin-fixed, paraffin-embedded tissue specimens. J Pathol 222: 41-51, 2010.

19. Sinha S, Dutta S, Datta K, Ghosh AK and Mukhopadhyay D: Von Hippel-Lindau gene product modulates TIS11B expression in renal cell carcinoma: impact on vascular endothelial growth factor expression in hypoxia. J Biol Chem 284: 3261032618, 2009.

20. Hauser S, Wulfken LM, Holdenrieder S, et al: Analysis of serum microRNAs (miR-26a-2*, miR-191, miR-337-3p and miR-378) as potential biomarkers in renal cell carcinoma. Cancer Epidemiol 36: 391-394, 2012.

21. Martínez-Salamanca JI1, Huang WC, Millán I, Bertini R, Bianco FJ, Carballido JA, Ciancio G, Hernández C, Herranz F, Haferkamp A, Hohenfellner M, Hu B, Koppie T, MartínezBallesteros C, Montorsi F, Palou J, Pontes JE, Russo $\mathrm{P}$, Terrone C, Villavicencio H, Volpe A, Libertino JA; International Renal Cell Carcinoma-Venous Thrombus Consortium: Prognostic impact of the 2009 UICC/AJCC TNM staging system for renal cell carcinoma with venous extension. Eur Urol 59: 120-127, 2011.
22. Xu J, Wang B, Xu Y, et al: Epigenetic regulation of HIF-1a in renal cancer cells involves HIF- $1 \alpha / 2 \alpha$ binding to a reverse hypoxia-response element. Oncogene 31: 1065-1072, 2012.

23. Youssef YM, White NM, Grigull J, et al: Accurate molecular classification of kidney cancer subtypes using microRNA signature. Eur Urol 59: 721-730, 2011.

24. Esteban MA, Tran MG, Harten SK, et al: Regulation of E-cadherin expression by $V H L$ and hypoxia-inducible factor. Cancer Res 66: 3567-3575, 2006

25. Redova M, Poprach A, Besse A, et al: MiR-210 expression in tumor tissue and in vitro effects of its silencing in renal cell carcinoma. Tumour Biol 34: 481-491, 2013.

26. Skrzypek K, Tertil M, Golda S, et al: Interplay between heme oxygenase-1 and miR-378 affects non-small cell lung carcinoma growth, vascularization, and metastasis. Antioxid Redox Signal 19: 644-660, 2013

27. Chen LT, Xu SD, Xu H, Zhang JF, Ning JF and Wang SF: MicroRNA-378 is associated with non-small cell lung cancer brain metastasis by promoting cell migration, invasion and tumor angiogenesis. Med Oncol 29: 1673-1680, 2012.

28. Lee DY, Deng Z, Wang CH and Yang BB: MicroRNA-378 promotes cell survival, tumor growth, and angiogenesis by targeting $\mathrm{SuFu}$ and Fus-1 expression. Proc Natl Acad Sci USA 104: 20350-20355, 2007

29. Jusufović E, Rijavec M, Keser D, et al: let-7b and miR-126 are down-regulated in tumor tissue and correlate with microvessel density and survival outcomes in non-small-cell lung cancer. PLoS One 7: e45577, 2012. 